\title{
... and more money for Paris laboratories
}

[PARIS] There are plans for increased investment in the research infrastructure of Paris, according to preliminary proposals for the multi-billion-franc scheme known as the 'University of the Third Millennium' (U3M). The proposals were discussed at a meeting of the programme's strategic committee last week (see opposite page).

The greater Paris area - Ile-de-Francehas been the main loser in recent national schemes to expand research and higher education. Many of its universities and laboratories are in a dire state of decay.

Immediate priorities are the controversial multi-million-franc removal of asbestos from the sprawling Jussieu campus in the Latin quarter (see Nature 382, 291; 1996), and the construction of a university beside the new Library of France in the south-east of Paris. The networking electronic integration of the new library with the university library system is also likely to be given high priority. There are also plans for investment in research facilities at the four new universities created just outside Paris by U3M's predecessor, 'University 2000'.

A renewal of efforts to develop the capital's research activities now also seems likely after a decade of separate government efforts to decentralize research from Ile-de-France. The area, which includes many government- funded research laboratories, accounts for less than a fifth of France's population and only a quarter of its student population, but carries out more than half the country's publicly funded research.

In 1992, the government demanded that thousands of research posts be transferred from Paris to regional centres by the end of the decade (see Nature 356, 373; 1992). The target set was to reduce the percentage of researchers in Paris to 40 per cent.

The Centre National de la Recherche Scientifique (CNRS) has moved 1,200 posts out of Paris, and, while 51.5 per cent of CNRS researchers worked in Ile-de-France in 1991, now less than 46 per cent do. This represents a fall of 8.7 per cent, whereas overall the number of CNRS researchers has grown by 4.5 per cent over the same period.

CNRS has achieved this shift largely through an affirmative employment policy, recruiting two researchers to regional centres for every one in the capital, and by investing in new regional centres.

Between 1990 and 1998 it spent FF1.2 billion (US\$212 million) on joint regional initiatives with the state and local government, a sum matched by these bodies. It created 31 centres of excellence outside Paris, including one in electronics in Lille, materials research in Bordeaux, structural biology at Grenoble, and even a centre for taste research at Dijon, the home of French mustard.

But CNRS is now reconsidering its strategy. An internal working group on regional affairs recently submitted a report to Catherine Bréchignac, the director general of CNRS, asking whether it is time to reconsider its policy of differential recruitment.

The working group, chaired by Jacques Sevin, director of strategy at CNRS, argues that the ageing of the Paris research population provides a case for renewed recruitment and that, unless it receives renewed attention, its science base is likely to suffer. Ile-deFrance is top of a new ranking of research activities (see below).

The group argues that, rather than decentralization from Ile-de-France, the development of regional metropoles should be the basis of the development strategy of CNRS.

The rehabilitation of Paris is likely to be included in the CNRS's regional policy, to be made public by Bréchignac later this year.

Sevin adds that regional development remains one of the biggest policy issues in CNRS. "The big work has been done, the task now is to consolidate," he says. He adds that CNRS needs to organize a critical mass of scientists in new regional centres and to devote more investment to equipment than to constructing new laboratories.

DeclanButler

\section{Map of research activities highlights disparity across European regions}

[PARIS] The geographical distribution and abundance of research is a burning political issue in France (see page opposite and above), and discussion of it at the European level seems likely to be stimulated by a map of research activity across Europe published by the Paris-based Observatoire des Sciences et des

Techniques (OST).

More than 80 per cent of the European Union's scientific output in terms of papers and patents is accounted for by just 67 regions on the map. The Paris area came top of the league, followed by London, Munich and Düsseldorf. Paris and London alone accounted for almost 10 per cent of Europe's scientific output.

The map (right) shows clearly that research activity is highest in the economically strong 'banana' extending along the axis of Milan, Rotterdam and London, with a skew towards
Paris and Lyons. Other striking features are that Italy and Germany are both split into two halves, one half rich in research, the other poor.

Research activity in Scotland is also revealed to be much stronger than might be widely believed, adds Remi Barré, director of OST, adding that Nordic countries also have strong research according to the map.

"The aim is to better understand the regional reality of scientific activity in Europe," says Barré, arguing that increasingly the regions, with their own substantial funds, are major players in research.

Barré cautions that the map is a simplified version of a detailed OST analysis, co-financed by the European Commission, of the research activities of the 445 regions in the member states of the European Union.

Regions were selected using

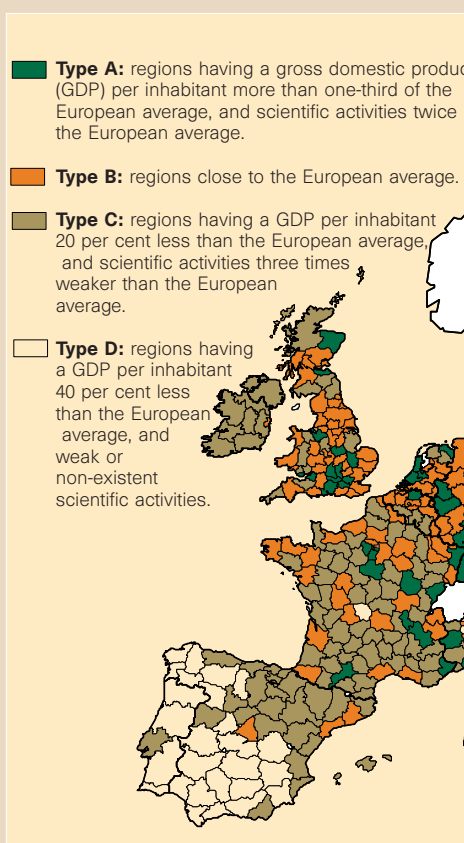

Source: III (SCI, COMPUMATH), INPI, OEB et EUROSTAT, analysis OST the commission's NUTS scale, which classes regions from NUTS 0 (a country) to NUTS 5 (a village). The OST analysis mostly included regions the size of NUTS
2 or 3 (roughly the size of a county, depending on the country), although tiny Luxembourg was counted as a single region, NUTS 0 . 